\title{
Assessment of Adnexal Masses among Indian Women using Ultrasound: A Prospective Study
}

\author{
Vishalkumar H Bhardava ${ }^{1}$, Mayur V. Khandedia ${ }^{2}$, Kalpesh K Patel ${ }^{3}$ \\ ${ }^{1}$ Assistant Professor, Department of Radiology, ${ }^{2}$ Associate Professor, Department of Radiology, ${ }^{3}$ Associate Professor, \\ Department of Radiology, Dhiraj Hospital, SBKS medical institute and research centre, Sumandeep Vidyapeeth University, \\ Piparia, Vadodara, India
}

Corresponding author: Mayur V Khandhedia, 2, Kanha Bunglow, Opp. Vrundavan Bunglow, Kubeshwar Marg, WaghodiyaDabhoi Ring Road, Vadodara-390019, India

DOI: http://dx.doi.org/10.21276/ijcmsr.2018.3.4.38

How to cite this article: Vishalkumar H Bhardava, Mayur V. Khandedia, Kalpesh K Patel. Assessment of adnexal masses among indian women using ultrasound: a prospective study. International Journal of Contemporary Medicine Surgery and Radiology. 2018;3(4):D167-D171.

\section{A B S T R A C T}

Introduction: Adnexal lesions are considered one of the most common disorders in gynecology practice. Imaging plays a crucial role in the evaluation of adnexal masses to differentiate malignant and benign lesions in order to provide appropriate treatment. Current trends toward early detection and characterization have increased the need for accurate imaging assessment of adnexal lesions prior to treatment. Ultrasound is the first-line imaging modality for assessing adnexal lesions. Hence, the aim of the present study was to evaluate the efficacy of ultrasonography in patients with adnexal masses and to correlate the results of ultrasound with histopathological findings.

Material and Methods: This was a prospective study done among 100 patients suspected to have adnexal masses was subjected to ultrasonography. Transabdominal ultrasonography (TAS) and transvaginal sonography (TVS) was conducted in clinically suspected cases of adnexal masses and incidentally found adnexal masses when patient is undergoing sonography. Unmarried female patients and paediatric patients of less than 15years of age were excluded from the study.

Results: The most commonly affected age group was 36-45 years. The major complaints were found to be of pain and history of lump in the abdomen. In this study, most common origin of adnexal lesions was from ovaries. On USG, $97.3 \%$ of benign masses were sonolucent. Only $2.74 \%$ of benign masses presented with low echogenicity with echogenic core. $96.3 \%$ of malignant masses had mixed echogenicity.

Conclusion: USG is recommended as a primary modality for diagnosing pelvic adnexal masses.

Keywords: Adnexal Mass, Benign, Malignancy, Ultrasound, Echogenicity, Sassone Scoring

\section{INTRODUCTION}

An adnexal mass is a tissue mass in the adnexa of the uterus, which refers to the space occupied by the uterus, ovaries and fallopian tubes. These can take the form of different types of malignant or benign masses. In premenopausal women, most adnexal masses are caused by ectopic pregnancy, ovarian cysts, tumours, polycystic ovaries and abscesses. After menopause, more likely causes include fibroid tumours, fibromas and malignant tumours. Adnexal masses represent a common finding among both premenopausal and postmenopausal women. ${ }^{1}$

According to International Ovarian Tumour Analysis (IOTA), an adnexal lesion is defined as 'the part of an ovary or an adnexal mass that is judged from an assessment of ultrasound images to be inconsistent with normal physiologic function'. The Adnexa of uterus refer to that anatomical area which is adjacent to the uterus, and contains the fallopian tube, ovary, and associated vessels, ligaments, and connective tissue. The most common locations for this type of mass to grow are in a fallopian tube or ovary. ${ }^{2}$
Adnexal masses are among the most frequent pathologic conditions in gynaecologic practice. Accurate diagnosis for adnexal masses is essential for appropriate clinical decisions. The benefits of such an accurate diagnosis include the possibility for a woman with high risk for malignancy to be referred to a gynaecologic oncologist for appropriate surgical staging and/or cyto-reductive surgery, and avoidance of unnecessary surgery in low-risk adnexal masses, Ultrasound is widely used for predicting malignancy in ovarian tumours. ${ }^{3}$ The incidence of adnexal masses in pregnancy ranges from 1 in 81 to 1 in 8000 pregnancies. These cysts may be asymptomatic and are found coincidently at the first trimester screening ultrasound or until their size increases the abdominal girth. Pain due to rupture, haemorrhage into the cyst, infection, venous congestion or torsion may be of sudden onset or of a more chronic nature. ${ }^{4}$

The primary goal of diagnostic evaluation of adnexal masses is to exclude malignancy. Ovarian cancer is the most lethal of the gynaecologic malignancies, with an overall 5-year survival rate of less than 40\%. According to ACOG guidelines (2008), women with adnexal masses have a $5-10 \%$ risk of requiring 
surgery, and those who undergo surgery have a 13-21\% chance of being diagnosed with ovarian cancer. ${ }^{5}$

Usually adnexal masses in pregnancy are imagiological findings, but when detected by palpation on physical exam, ultrasound should be the first step to characterize the lesion. Transabdominal and/or transvaginal ultrasound allows morpho-dimensional evaluation and assessment of mass vascularization and growth, as well as observation of the contralateral ovary and detection of other malignant signs, such as the presence of ascites and peritoneal carcinomatosis. ${ }^{6}$ Several ultrasonographic features were associated, in nonpregnant women, with an increased risk of malignancy, such as irregular solid tumour, multi-locular and irregular masses with more than $10 \mathrm{~cm}$, septa thicker than 2-3 mm, presence of more than three papillary projections, exuberant blood flow, and presence of ascites or peritoneal masses. Nevertheless, ultrasound evaluation of adnexal masses in pregnant women has some limitations. ${ }^{7}$

Increased uterine volume makes evaluation difficult after 20 weeks of gestation. USG and Doppler is preliminary and baseline investigation for any mass forming adnexal lesion. High resolution USG method can detect very small lesion at early stage. Doppler study of adnexa demonstrates normal vasculature as well as neovascularity in adnexal tumours and adjacent tissue if it is infiltrated by lesion. ${ }^{8}$

Recent studies have reported that radiological investigations allow detailed evaluation of anatomy and pathology of female adnexa. Specifically, one can document type of lesion, size and site of lesion, its benign and malignant potential. It also provides clue to support specific diagnosis. ${ }^{9}$ Therefore, the aim of the present study was to evaluate the efficacy of ultrasonography in patients with adnexal masses and to correlate the results of ultrasound with histopathological findings.

\section{MATERIAL AND METHODS}

This was a prospective study which was conducted among 100 patients during the period of march 2016 to may 2018. The study group consisted of mainly patients from different parts of Gujarat and also some from the states like Rajasthan and Madhya Pradesh.The cases were recruited from the Dhiraj Hospital attached to SBKS Medical institute and research centre, PIPARIA VADODARA). All eligible patients were properly counselled and gave informed consent before entry into the study. The women underwent ultrasound only if transabdominal ultrasonography (TAS) and transvaginal sonography (TVS) was conducted in clinically suspected cases of adnexal masses. Incidentally found adnexal masses when patient is undergoing sonography. Unmarried female patients (since TVS is contraindicated) and paediatric patients who were less than 15 years were excluded from the study.

Detailed menstrual, obstetric and medical histories of each patient were taken and general, physical, systemic and gynecological examination was done. Relevant investigations were done according to clinical findings. All of them were subjected to transabdominal ultrasonography with full bladder technique with $3.5 \mathrm{MHz}$ probe and then transvaginal sonogrpahy with empty bladder technique with $6.5 \mathrm{MHz}$ was carried out.

Initially the patients were evaluated with an abdominal transducer to evaluate potential pathologic conditions outside the focal length of the vaginal transducer. For transvaginal scan, transducer was prepared for use by first applying standard coupling gel followed by a condom which was again lubricated with coupling gel before insertion. The transducer was introduced into posterior vaginal fornix when uterus was retroverted and into anterior vaginal fornix when it was anteverted.

Complete pelvic survey was performed. Observations included size, shape and echotexture of the adnexal masses in sagittal and transverse planes. Sassone scoring system was applied to differentiate benign and malignant ovarian tumors. ${ }^{10}$ This scoring system takes into account for the inner wall structure, wall thickness, septa and echogenicity giving a scoring ranging from 4-15. The final diagnosis was made by histopathologic examination following total abdominal hysterectomy or biopsy. All pathology reports were reviewed. The findings of sonography were correlated with histologic findings, which were taken as gold standard.

\begin{tabular}{|c|c|c|c|c|}
\hline \multirow[t]{2}{*}{ Score } & \multicolumn{4}{|l|}{ Variables } \\
\hline & $\begin{array}{l}\text { Inner wall struc- } \\
\text { ture }(\mathrm{mm})\end{array}$ & $\begin{array}{l}\text { Wall thickness } \\
(\mathrm{mm})\end{array}$ & Septa (mm) & Echogenicity \\
\hline 1 & Smooth & Thin $\leq 3 \mathrm{~mm}$ & No septa & Sonolucent \\
\hline 2 & Irregular $\leq 3 \mathrm{~mm}$ & Thick >3 mm & Thin $\leq 3 \mathrm{~mm}$ & Low echogenicity \\
\hline 3 & Papillarities $>3 \mathrm{~mm}$ & $\begin{array}{l}\text { Not applicable } \\
\text { (mostly solid) }\end{array}$ & Thick $>3 \mathrm{~mm}$ & $\begin{array}{l}\text { Low echogenicity } \\
\text { with echogenic core }\end{array}$ \\
\hline 4 & $\begin{array}{l}\text { Not applicable } \\
\text { mostly Solid }\end{array}$ & - & - & Mixed echogenicity \\
\hline 5 & - & - & - & High echogenicity \\
\hline
\end{tabular}

\section{Sassone scoring system ${ }^{10}$}

Maximum score $=15$, Minimum score $=4$

Score $>9$ indicates malignancy

With the advent of high-frequency transvaginal ultrasonography, new opportunities are presented to better define ovarian lesions. The scoring system was useful in distinguishing benign from malignant masses.

\section{STATISTICAL ANALYSIS}

Results were expressed as mean $\pm \mathrm{SD}$ and proportions as percentages. Diagnostic validity tests were performed to assess the diagnostic value of sonographic and clinical diagnosis.

\section{RESULTS}

In the present study, $40 \%$ of cases were from the age group $36-45$ years followed by $23 \%$ in $46-55$ years and $22 \%$ in $26-35$ years. Least i.e. $2 \%$ of patients were from below $16-25$ years followed by $4 \%$ in $66-75$ years of age and $9 \%$ in 56-65years of age. (Table no. 1). In the present study, $43 \%$ of patients had pain followed by history of lump in the abdomen and loss of weight in $10 \%$ of the patients along with backache among $6 \%$ of patients and least subjects i.e. 3\% had Amenorrhea (Table no. 2).

In Table no. 3 it was observed that $86 \%$ of the patients had right adnexa and 4\% had left adnexa followed by bilateral adnexa among $10 \%$ of the patients.

In Table no. 4 patients were categorised according to 


\begin{tabular}{|l|c|c|}
\hline Age group in years & No. of cases & Percentage\% \\
\hline $16-25$ & 2 & 2 \\
\hline $26-35$ & 22 & 22 \\
\hline $36-45$ & 40 & 40 \\
\hline $46-55$ & 23 & 23 \\
\hline $56-65$ & 9 & 9 \\
\hline $66-75$ & 4 & 4 \\
\hline Total & 100 & 100 \\
\hline \multicolumn{2}{|c|}{ Table-1: Shows the distribution of age among study subjects } \\
\hline
\end{tabular}

\begin{tabular}{|l|c|c|}
\hline Echogenicity score & Benign(73) & Malignant(27) \\
\hline Sonolucent-1 & $71(97.3 \%)$ & $1(3.7 \%)$ \\
\hline Low echogenicity & 0 & 0 \\
\hline $\begin{array}{l}\text { Low echogenicity with Echogen- } \\
\text { ic core }\end{array}$ & $2(2.74 \%)$ & 0 \\
\hline Mixed echogenicity & 0 & $26(96.3 \%)$ \\
\hline High echogenicity & 0 & 0 \\
\hline \multicolumn{2}{|l|}{ Table-6: Shows the distribution of echogenicity scores among } \\
study subjects \\
\hline
\end{tabular}

\begin{tabular}{|l|c|c|}
\hline Clinical features & No of cases & Percentage\% \\
\hline Mass PA & 83 & 83 \\
\hline Pain & 43 & 43 \\
\hline Backache & 6 & 6 \\
\hline Discharge & 9 & 9 \\
\hline Loss of weight & 10 & 10 \\
\hline Amenorrhea & 3 & 3 \\
\hline $\begin{array}{l}\text { Menstrual cycle } \\
\text { Regular } \\
\text { Irregular }\end{array}$ & 48 & 48 \\
\hline \multicolumn{2}{|c|}{ Table-2: Shows the distribution of clinical features among } \\
study subjects \\
\hline
\end{tabular}

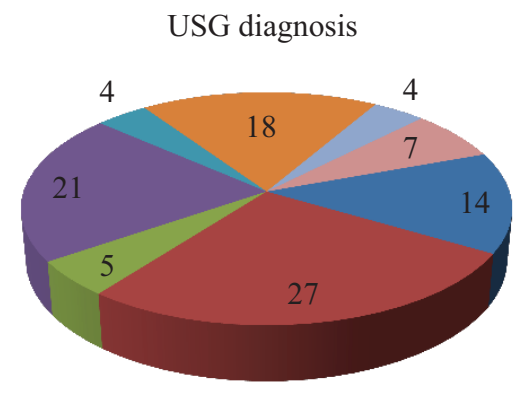
- Dermoid cyst
Benign right ov cyst
B/L ovarian cysts
- Right ov complex cyst
- Right hydrosalpinx
- Right ov malignancy
- Left ov malignancy
B/L ov malignancy

Graph-1: Shows the distribution of lesions diagnosed through USG among study subjects

\begin{tabular}{|l|c|c|}
\hline Site & No of cases & Percentage \\
\hline Right adnexa & 86 & 86 \\
\hline Bilateral adnexa & 10 & 10 \\
\hline Left adnexa & 4 & 4 \\
\hline Total & 100 & 100 \\
\hline \multicolumn{2}{|c|}{ Table-3: Shows the site of adnexa among study subjects } \\
\hline
\end{tabular}

\begin{tabular}{|l|c|c|}
\hline Size (in cms) & Benign & Malignant \\
\hline $5-9$ & $62(84.93 \%)$ & $2(7.40 \%)$ \\
\hline $10-14$ & $9(12.3 \%)$ & $19(70.37 \%)$ \\
\hline$>15$ & $2(2.73 \%)$ & $6(22.22 \%)$ \\
\hline \multicolumn{2}{|c|}{ Table-4: Shows the size of adnexa among study subjects } \\
\hline
\end{tabular}

\begin{tabular}{|l|c|c|}
\hline Score & Benign $(\mathbf{n}=\mathbf{7 3})$ & Malignant $\mathbf{( n = 2 7 )}$ \\
\hline 4 & $30(41.2 \%)$ & 0 \\
\hline 5 & $16(21.2 \%)$ & 0 \\
\hline 6 & $13(21.92 \%)$ & 0 \\
\hline 7 & 0 & 0 \\
\hline 8 & $14(19.2 \%)$ & 0 \\
\hline 9 & 0 & 0 \\
\hline 10 & 0 & $1(3.7 \%)$ \\
\hline 11 & 0 & $3(11.11 \%)$ \\
\hline 12 & 0 & 0 \\
\hline 13 & 0 & $5(18.52 \%)$ \\
\hline 14 & 0 & $18(66.67 \%)$ \\
\hline 15 & 0 & 0 \\
\hline \multicolumn{2}{|c|}{ Table-5: Shows Sassone Sonographic Score for Benign and } \\
\hline \multicolumn{2}{|c|}{ Malignant Tumor } \\
\hline
\end{tabular}

sonographic size in different groups from $5 \mathrm{~cm}$ to more than $15 \mathrm{cms}$. Approximately $84.93 \%$ of benign masses were $5-9$ $\mathrm{cms}$ in size as compared to $7.40 \%$ of malignant masses. 9 patients $(12.3 \%)$ out of 73 benign masses were of size 10-

Histopathological diagnosis

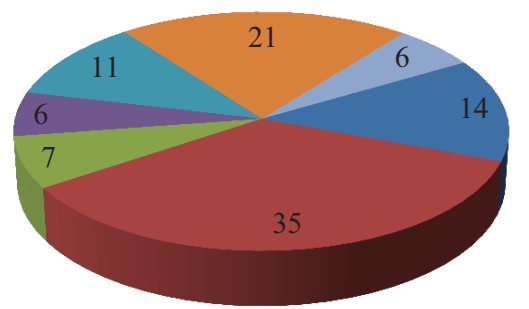

- Dermoid cyst

- Serous cystadenoma

TOA

Endometriosis

Mucinous cystadenoma

PDAC

Serous cysadenoca

Graph-2: Shows distribution of lesions according to histopathological findings among study subjects

$14 \mathrm{cms}$ as compared to $70.37 \%$ of malignant masses. Only $2.73 \%$ of benign masses were of more than $15 \mathrm{cms}$.

In Table no. 5 , it was found that adnexal masses were grouped according to the sonographic score varying from 4 to more than 11 . None of the malignant masses had score ranging from 4 to 9 . It was found that 14 out of 73 benign masses had score of 8 . Most of the benign masses had score of 4, 5 and 6 . In Table no.6, it was seen that $97.3 \%$ of benign masses were sonolucent. Only $2.74 \%$ of benign masses presented with low echogenicity with echogenic core. About $96.3 \%$ of malignant masses had mixed echogenicity.

In Graph no. 2 it was seen that benign ovarian tumours form the majority of cases followed by right ovarian complex cyst and right ovarian malignancy. In Graph no. 2 it was observed that histopathological examination revealed majority of benign lesions which were serous cystadenoma and mainly malignant lesions were poorly differentiated adenocarcinoma.

\section{DISCUSSION}

Tumour size had frequently been identified as a risk factor for malignancy. Correlating the sonographic size with malignancy it was observed in our study that most of the tumours of less than $9 \mathrm{cms}$ were benign and only $7.40 \%$ of malignant masses. Most malignant tumours were more than 
$10 \mathrm{cms}$. These findings were in consistent with the study done by Anuradha khanna et al where author stated that most of the tumours less than $7 \mathrm{~cm}$ were benign (79.4\%) as compared to only $19.4 \%$ malignant masses. Also Rulin et al found that malignancy was usually seen in large tumours but later in 1989 Feur et al found out that size alone is not a sufficient indicator of malignancy. ${ }^{11,12,13}$

Following the Sassone scoring system and taking cut-off score of more than 9 as an indicator of malignancy, it was found that $100 \%$ of malignant masses with score $>9$ and all the benign masses had score $<9$. Zanetta et al also found out that malignant tumour had higher sonographic score than benign masses. ${ }^{14}$

To calculate sonographic score, certain sonographic features like inner wall structure, wall thickness, septa and echogenicity were studied and scoring was done for each sonographic feature. None of the malignant masses had smooth surface on the inner wall as compared to $67.12 \%$ of benign masses. All malignant tumours had solid areas but any of the benign masses showed these features. In the present study, none of the benign masses had score 3 or 4 for inner wall structure but it was seen in all malignant masses. Only $32.9 \%$ of benign masses had irregular inner wall structure. In a study conducted by Anuradha Khanna et al it was found out that none of the benign adnexal masses had score 3 or 4 for inner wall structure but it was seen in 175 and $28.8 \%$ of malignant masses.

In this study, wall thickness $<3 \mathrm{~mm}$ was seen in $97.3 \%$ of benign masses and none of the malignant masses. Thick wall was seen in $2.74 \%$ of benign masses. Solid wall was seen in $70.4 \%$ malignant masses. Anuradha Khanna et al found out that wall thickness $<3 \mathrm{~mm}$ seen in $75 \%$ of benign masses but none in malignant masses. Thick and solid wall was seen in $73.1 \%$ and $26.8 \%$ of malignant masses but only in $24.8 \%$ and $0 \%$ benign masses.

Granberg et al found $95 \%$ and $70 \%$ malignancy in tumours with papillary excrescence and solid components. Zanetta et al also found out that malignancy is associated with masses with thick wall and solid areas. In our study, all tumours with solid components were malignant. In this study, septa was absent in $75.34 \%$ of benign masses and $11.11 \%$ in malignant masses. ${ }^{11,15}$ Thin septa were seen in $24.7 \%$ of benign masses. Thick septa were seen in $88.9 \%$ malignant masses. Anuradha Khanna et al found out that septa was absent in $68.1 \%$ of benign and only $4.7 \%$ on malignant masses. Thin septa were seen in $29.6 \%$ and thick septa in only $1.1 \%$ of benign masses but $2.4 \%$ and $73.1 \%$ of malignant masses had thin and thick septa respectively. Requard et al also found that majority of masses with thick was malignant and thin septa did not rule out malignancy many malignant tumours had both thin and thick septa. ${ }^{11,16}$

In our study $3.7 \%$ of the malignant masses were sonolucent with low echogenicity. $96.3 \%$ of malignant masses had mixed echogenicity and none of benign masses showed mixed echogenicity. In a similar study done by Anuradha Khanna et al found out that $38.2 \%$ and $14.8 \%$ cases of benign masses were either sonolucent or with low echogenicity but $46.3 \%, 39 \%$ and $14.6 \%$ cases of malignant masses presented with low echogenicity with low echogenic core, mixed echogenicity and high echogenicity respectively. Moyle et al also found out that risk of malignancy increases with increase in internal echoes. Many investigators have also related echogenic tissue with the tumour with malignancy. ${ }^{11,17}$

In this study, out of total 73 benign cases, Sassone scoring by ultrasonography labelled 70 cases as benign and missed 3 cases which were actually benign. This study showed that sensitivity of ultrasonographic Sassone scoring system, sensitivity-96.3\%, specificity-95.9\%, positive predictive value- $89.7 \%$ and negative predictive value- $98.6 \%$. Sassone et al found that sensitivity of $100 \%$, specificity $83 \%$, positive predictive value- $37 \%$ and negative predictive value- $100 \%$ of sonographic scoring system. Another study by Timor-Tritsch et al found sensitivity, specificity and positive predictive value of sonographic score $94 \%, 87 \%$ and $60 \%$ respectively. ${ }^{10,18}$

\section{CONCLUSION}

The present study showed that the majority of benign ovarian tumours were serous cyst adenoma and all malignant tumours were found to be serous cyst adenocarcinoma and poorly differentiated adenocarcinoma. Thus, ultrasound is the main diagnostic imaging modality prior to treatment. Improved detection and characterization of ovarian tumour contributes to better diagnostic accuracy and consequently reduction of false-positive findings and invasive procedures, which leads to a significant reduction of morbidity and mortality from ovarian cancer.

\section{REFERENCES}

1. Fishman DA, Cohen L, Blank SV, et al. The role of ultrasound evaluation in the detection of early-stage epithelial ovarian cancer. Am J Obstet Gynecol 2005; 192(3):1214-1221.

2. Maria Elisabetta Coccia, Francesca Rizzello, Chiara Romanelli, Tommaso Capezzuoli. Adnexal masses: what is the role of ultrasonographic imaging? Arch Gynecol Obstet 2014; 290 (2):843-854.

3. Timmerman D, Ameye L, Fischerova D, et al. Simple ultrasound rules to distinguish between benign and malignant adnexal masses before surgery: prospective validation by IOTA group. BMJ 2010; 341 (5):1-8.

4. Sayasneh A, Ekechi C, Ferrara L, et al. The characteristic ultrasound features of specific types of ovarian pathology (review). Int J Oncol 2015; 46 (2):445-458.

5. Graham L. ACOG releases guidelines on management of adnexal masses. American College of Obstetricians and Gynecologists. Am Fam Physician 2008; 77(5):1320-1323.

6. F.V. Coakely. Staging ovarian cancer: role of imaging. Radiol Clin N Am 2002; 40(3):609-636.

7. Dodson MG, Pache TD. Basic Principles and Equipment. In: Dodson MG.ed. Transvaginal Ultrasound., $2^{\text {nd }}$ Edition New York: Churchill Livingstone; 1995:p.17-24.

8. Mendelson EB, Bohm-Veliz M, Joseph N, Neiman HL. Gynecologic imaging: comparision of transabdominal and transvaginal sonography. Radiology 1988; 166(6):321-4.

9. S.A.Funt, L.E.Hann. Detection and characterization of adnexal masses. Radiol Clin N Am 2002; 40(6):591- 
608.

10. Sassone AM, Timor Tritsch IE, Anner et al. Transvaginal sonographic characteristics of ovarian disease. Evaluation of new scoring system to predict ovarian malignancy. Obstet Gynecol 1991; 78(4):70-76.

11. Anuradha K Shweta G, Shukla R C, Mohan K. Evaluation of sassone sonographic scoring system in various adnexal masses. Ultrasound International Dec. 2001; 72(2):148-52.

12. Rulin MC, Preston AL. Adnexal masses in postmenopausal women. Obstet Gynecol 1987; 70:578.

13. Feuer GA, Sherehuk M, Calong A. Normal sized ovary carcinoma syndrome. Obstet Gynecol 1989; 73(6):786.

14. Zanetta G, Vergani P, Lissoni A et al. Color Doppler ultrasound in the preoperative assessment of adnexal masses. Acta Obstetrica Gynecol 1993; 637-41.

15. Granberg S, Norstrom A, Wilkland H. Tumors in the lower pelvis as imaged by vaginal sonography. Gynecol Oncol 1990; 37(1):224-9.

16. Requard CK, Mettle FA, Wicks JD. Preoperative sonography of malignant ovarian neoplasms. AJR Am J Roentgenol 1981; 137(3):79-82.

17. Moyle J, Rochester D, Sider L, Shrock K, Krause P. Sonography of ovarian tumors: predictability of tumor type. AJR Am J Roentgenol 1983; 141(5):637-41.

18. Timor Tritsch IE, Rottem S. Transvaginal Sonography, $2^{\text {nd }}$ Edition New York, Elsevier, 1991:p.145.

Source of Support: Nil; Conflict of Interest: None

Submitted: 22-11-2018; Accepted: 15-12-2018; Published online: 31-12-2018 